\title{
The Countryside in Indonesian Contemporary Art and Media
}

\section{From Distant Horizons to Traversing Drones}

\author{
Edwin Jurriëns \\ The University of Melbourne \\ edwin.jurriens@unimelb.edu.au
}

\begin{abstract}
This article analyses explorations of social and environmental problems and solutions in artistic representations of the Indonesian countryside and rural society, culture, and wisdom. It focuses on urban-rural creative collaborations that combine traditional culture and knowledge with modern technology and media, such as drones and the Internet, to empower local communities, promote artistic innovation, and enhance environmental sustainability. It seeks to demonstrate that contemporary art and media strengthen the urban-rural network and the accessibility and exchange of creative ideas and information. At the same time, the author argues that some of the causes of cultural conflict and anthropogenic disaster are embedded in forms of audio-visual representation itself. The display of urban-rural encounters in art festivals and social media can even instigate new forms of surveillance, and power and knowledge hierarchies, or reinforce regimes of consumer culture, partially responsible for the very problems the audio-visual representations and collaborations seek to address.
\end{abstract}

\section{Keywords}

contemporary art - rural culture - environmental problems - creative collaboration Indonesia

This article analyses explorations of social and environmental problems and solutions in artistic representations of the Indonesian countryside and rural society, culture, and wisdom. It focuses on urban-rural creative collaborations 
that combine traditional culture and knowledge with modern technology and media, such as drones and the Internet, to empower local communities, promote artistic innovation, and enhance environmental sustainability. It critically examines these representations and collaborations by positioning them in a history of artistic engagements with the environment and the countryside in the Indonesian archipelago, dating back to modern painting traditions during colonial times.

The main case study of this article deals with collaborations between the Bandung-based Common Room Networks Foundation and the Kasepuhan Ciptagelar community in rural West Java. These collaborations include the expansion of the community's digital infrastructure, the geospatial mapping of the Ciptagelar territory, the digital collection and distribution of traditional knowledge, and joint artistic projects. Artists from Kasepuhan Ciptagelar have also hosted and worked with international artists, sometimes through the Common Room Networks Foundation, and have presented their art and community at festivals, conventions, and media outlets in Asia, Europe, Australia, and North America. This includes the recent, multi-year international collaborative project Age of Wonderland, initiated by Baltan Laboratories, HIVos, and the Dutch Design Foundation in the city of Eindhoven in the Netherlands. There are also numerous audio-visual art projects, documentaries, news broadcasts, and amateur videos related to Kasepuhan Ciptagelar on YouTube and other Internet platforms. My article analyses audio-visual forms of creativity that are accessible on the various digital platforms, but it is also based on ongoing observations of the art scene and the media in West Java since 1997 and conversations with, and research about, the Common Room Networks Foundation and other visual artists since 2008 .

This article seeks to demonstrate that contemporary art and media strengthen the urban-rural network and the accessibility and exchange of creative ideas and information. In this sense, they express a desire for coevality, or the creation of a shared space for respecting differences and seeking common grounds. I show that professional art production, social media, and community initiatives have become intertwined and blurred in contemporary activism, notwithstanding some of the differences in logics, assumptions, and audiences underlying the various genres. I also argue that some of the causes of cultural conflict and anthropogenic disaster are embedded in forms of audio-visual representation itself, including the display of urban-rural encounters in art festivals and social media. Art and social media projects highlighting social and environmental deterioration do not always cover the broader political contexts and questions of agency and responsibility. They can even instigate new forms of surveillance, and power and knowledge hierarchies, or reinforce regimes of 
consumer culture, partially responsible for the very problems the audio-visual representations and collaborations seek to address.

Art is, to a greater or lesser extent, an expression of the socio-political conditions in which it is created. In that sense, contemporary art is not any different from other forms of art. Unlike other forms of art, however, it turns the contemporary into a dominant theme and integral aspect of its media, styles, and sites of display. The contemporary here implies 'presentness, being in the present, beings who are present to each other, to the time they happen to be in' (Smith 2008:8). Contemporary art acknowledges 'the power of the present' and does not see it merely as a 'transition from the past to the future' (Smith 2008:7). This urgency of presentness is not found in other styles, such as modern realism, which aims at outlasting its 'necessary contemporaneity' and secure its place in eternity (Smith 2008:4). Contemporary art, on the other hand, establishes and thematizes connections with people, objects, and environments in the here and now. It is less concerned with representing or imagining the conditions of the 'there and then', although its focus on presentness does not exclude engagements with the past or visions for the future.

Terry Smith (2013, 2016) identifies various 'contemporaneous currents', each with their own artistic ways of engaging with the world, and different worlds within the world. These engagements can range from re-adaptations of modernist and postmodernist formats to anti-imperialist, nationalist, internationalist, or cosmopolitan imagery (Smith 2013:189). Recent information and communication technology has also facilitated the emergence of interactive, Do-ItYourself (DIY) style art works, spaces, and networks, which examine the realities of the present and explore small-scale, alternative scenarios for the future (Smith 2016:14, 25). In Smith's (2016:12) view, this last contemporaneous current is not about erasing difference but about respecting the identity of others and '[picturing] all of the worlds in which we live in their real relation to each other; work together to create and sustain a viable sense of place for each of us; establish and maintain coeval connectivity between worlds and places'. It expresses a desire for coevality, or 'the coeval commons', which is deemed necessary for dealing with the major challenges of our age, including climate change and the risk of the 'Sixth Extinction' (Smith 2016:14, 25).

In Indonesian contemporary art, new-media art collectives have expressed this desire for coevality by bringing different agents, materials, and spaces, including previously unnoticed or disregarded ones, in creative and critical 
dialogue with each other. Their main focus has been on exploring the sociocultural, political, and material dimensions of urban life in Indonesia. They have addressed urban problems and solutions by creating their own virtual and physical community spaces; collaborative and/or interactive, process-based multi-media works; and interdisciplinary, multi-actor networks. Some of the most active collectives include ruangrupa (established in 2000) and Forum Lenteng (2003) in Jakarta; the Common Room Networks Foundation (2001/ 20o6) in Bandung; Ruang Mes 56 (2002), The House of Natural Fiber (1999), XXLab (2013), and Lifepatch (2012) in Yogyakarta; and WAFT (2011) in Surabaya (Jurriëns 2014:174-7). ${ }^{1}$ Their emergence since the late 199os has been steered by the greater freedom of expression after the fall of President Soeharto's New Order regime (1967-1998) and the increased availability of digital hard- and software for creative production, distribution, and consumption, among others.

Their desire for coevality has not only been expressed through their cosmopolitan networking with similar collectives elsewhere in the world but also through collaborations with NGOS, community groups, schools, universities, religious organizations, businesses, and regional and national governments in Indonesia. Their creativity and criticality play a crucial role in mediating between groups that rarely meet in daily life and in highlighting, and possibly providing solutions to, pressing contemporary issues such as poverty and pollution, which tend to be neglected or underexplored in the mainstream media, government policies, and business plans. Their spaces, festivals, installations, performances, screenings, and wall paintings are tools to reflect on, and both physically and symbolically intervene in, the urban environment.

Since the mid 200os, some of the collectives have made efforts to expand their scale of coevality, and to network and collaborate with Indonesian communities that are normally considered 'traditional', rural, or semi-rural. From an art-historical perspective, 'the significance of this shift of emphasis (from the urban to the rural) should not be underestimated in an art world that continues to privilege the city as the only relevant site of art practice and dissemination' (Kester 2011:99). Grant Kester (2011:99) refers to projects such as Huit Facettes in Senegal, Dialogue in India, and Ala Plastica in Argentina, which stand out for 'drawing attention to the complex changes being registered in the countryside through the process of globalization, and exploring the necessary interdependence of the urban and the rural'. In the Indonesian context,

1 A different, non-urban perspective has been offered by the Jatiwangi Art Factory (established in 2005), an interdisciplinary, multi-media collective in the semi-rural Majalengka regency in West Java. 
the urban-rural interactions often serve the dual purpose of stimulating the socio-economic development of rural areas and promoting urban renewal and environmental sustainability through the exploration of traditional knowledge sources. These partnerships have been fruitful in some respects, and challenging and problematic in others, as I will discuss in the remainder of this article.

The desire for creating common ground among diverse urban and rural groups is reflected in the name of the Non-Profit Organization (NPO) Common Room Networks Foundation. This foundation was established in 2006 as a continuation of the Common Room cultural centre (established in 2003) and the Bandung Center for New Media Art (BCfNMA, established in 2001). It presents itself as an open platform for the study and development of art, culture, and information and communications technology (ICT) (Jurriëns 2014:179-80). Its members have analysed Bandung's urban development from the perspectives of cultural diversity, the use of open-source technology, and environmental sustainability. They believe that open-source media technology is an effective means to create awareness about the problems caused by the worldwide increase in urbanization, such as intergroup conflicts, the degradation of living conditions, and the decrease in natural resources (Jurriëns 2014:184).

One of their routine activities has been the Nu-Substance festival for newmedia art and urban ecology, organized annually since 2007..$^{2}$ The aim of the festival is to explore how art and technology can involve ordinary citizens in finding solutions or alternatives to some of the core problems of urbanization (Jurriëns 2014:184). The Common Room Network Foundation's founder, Gustaff Harriman Iskandar, also co-initiated the Bandung Creative City Forum (BCCF) in 2008. Although supportive of the local creative industry, Iskandar and his colleagues are concerned about the impact of this and other types of economic activity on the various social, material, and natural aspects of people's urban environment. They explain that official policies tend to focus on the material infrastructure of cities rather than the more urgent issue of creating human capital through increasing people's access to education and information (Jurriëns 2014:181-2).

2 Idhar Resmadi, 'Nu-Substance festival 2007-2012 (The Common Room Networks Foundation, 2013)', 12-6-2017. https://idhar-resmadi.net/tag/commonroom (accessed 14-9-2018). 
While initially focusing on the socio-political and cultural dynamics in the city of Bandung, since 2013 the Common Room Networks Foundation has shifted its direction to 'urban-rural development initiatives'. ${ }^{3}$ This new, broader perspective on urban-rural relations has been partially motived by personal reasons. Iskandar and his wife, the Common Room Networks Foundation cofounder Reina Wulansari, have been searching for a healthier environment for their family outside the densely populated and air-, water-, and soil-polluted Bandung metropolis. In recent years, they have been alternating between their house in Bandung and their farm in the mountainous countryside near the city of Sukabumi, Iskandar's place of birth. ${ }^{4}$ Their experiences in rural West Java contribute relevant knowledge to the Common Room Networks Foundation's projects on urban ecology, the creative industry, and environmental sustainability.

The Common Room Networks Foundation and similar new-media art collectives provide their own responses to environmental problems, which build on, and deviate from, other artistic engagements with nature and society. They focus on interdisciplinary research and collaborative art projects, and mix old and new technologies to create utopian scenarios and practical solutions for a more sustainable future (Jurriëns 2017). One of the other approaches in Indonesian contemporary art includes critical, socio-political commentary on the pollution and exploitation of nature caused by corporate and government power. Examples are the multimedia works by artists like Moelyono (b. 1957), Tisna Sanjaya (b. 1958), Arahmaiani (b. 1961), Setu Legi (b. 1971), Iwan Wijono (b. 1971), Heri Budiman (b. 1971), Made Muliana Bayak (b. 1980), and Maryanto (b. 1977) and art collectives like Gerakan Seni Rupa Baru (GSRB, the New Art Movement) of the 1970s and 1980s and Taring Padi since the late 199os (Jurriëns 2019).

The works of 'modernist' Indonesian painters such as Ahmad Sadali (19241987), Nyoman Erawan (b. 1958), Bagong Kussudiardjo (1928-2004), and Tulus Warsito (b. 1953) encompass more stylized or abstract representations of the environment, which often underline the spiritual dimensions of the environment by drawing links between belief, culture, and nature (Fischer 199o; Wright 1994). Another approach can be traced back to realist or idealist landscape paintings during Dutch colonialism, including the work of Abdullah Suriosubroto (1878-1941), Mas Pirngadi (1875-1936), Wakidi (1889-1979), and Basoeki Abdullah (1915-1993). This style also includes the contemporary commercial

3 '2015 GALA ASIA introduction'. http://greenartlaballiance.eu/wp-content/uploads/2015/11/ GALA-ASIA-Introduction.pdf (accessed 14-9-2018).

4 Iskandar, personal communication, 13-8-2018. 
landscape paintings that are offered to tourists in small galleries and roadside shops in the streets of Yogyakarta and Bali. This style is commonly referred to as 'Mooi Indië' (Beautiful Indies), a term promoted by the nationalist painter Sindudarsono Sudjojono (1913-1986) in condemnation of the sheer absence of socio-political references in these paintings (Protschky 2011:83-4; Van Brakel 2009:54-5; Spanjaard 2016:15-7).

\section{3}

\section{The 'Beautiful Indies'}

The Common Room Networks Foundation and other experimental new-media art groups share with some of the more ideologically oriented artists and collectives a concern about the interrelations between environmental destruction and socio-political problems. Like the abstract painters, they have an interest in cultural heritage and local spiritual values. With their focus on local empowerment, social participation, and creative collaboration, they seem to be furthest removed from the Beautiful Indies approach, which has been shaped by colonial views of the natural and social environment. However, both the colonial and contemporary artistic practices involve the representation of landscapes and the mapping of territories, each implying their own visual hierarchies and socio-political interests.

According to Susie Protschky (2011:73), 'the panoramic perspectives typical of mooi Indië paintings elegantly captured the strategic and commercial value of colonized land while conveniently eliding the practical details of its conquest, which frequently involved violence, exploitation and destruction of the environment'. In its nineteenth- and twentieth-century representations, this style provided idealized representations of tropical landscapes, seemingly untouched by human intervention. It included rice fields, palm trees, mountains, and subsistence farming but excluded images of commercial agriculture. By using panoramic views with distant horizons, details of the human costs and environmental impact of the colonial plantation system were left out of sight (Protschky 2011:73-4). The linear perspective objectified the landscape and confirmed the centrality and stability of the Western viewer. It presented nature as an object to be further explored and exploited, while simultaneously naturalizing and historicizing radical changes to the environment (Protschky 2011:82).

Colonial photography since the mid nineteenth century not only embraced Beautiful Indies conventions of tropical beauty but also documented Western industrial interventions in the landscape (Protschky 2011:91). The photographs celebrated modernity, technological progress, and the implementation 
of order and discipline in its close-up representations of coffee, tea, and sugar plantations and, from the first half of the twentieth century, aerial views of roads, bridges, railway tracks, and factories. The photographs were used to promote commercial corporations, develop the careers of civil servants, and serve scholarly, scientific, and military purposes. They were also sold as souvenirs for family albums or shown as artistic and educational materials at exhibitions and world fairs (Protschky 2011:89-92). ${ }^{5}$ The perspectives used included panoramas, bird's-eye views, and views from ship decks (Protschky 2011:3043). The focus on coastlines and distant landscapes kept interior kingdoms and communities out of sight and gave them an aura of mystique (Protschky 2011:39).

Contemporary urban-rural engagements simultaneously deviate from, and steer into new directions, some of the Beautiful Indies conventions. One major change is the enhanced accessibility of the rural communities, and their involvement in their own representations. They are no longer located in a distant space and time, notwithstanding their preservation of traditional notions of space and time. Some of the new technologies and perspectives include digital networks, drones, and car-mounted cameras that traverse the natural environment with flexibility, able to constantly zoom in/zoom out. These modern media and creative tools can be controlled by individuals and facilitate almost instantaneous communication and information-sharing with recipients worldwide. They are not without new forms of surveillance and control, however. They present contemporary forms of mapping, objectification, and commoditization, which include, exclude, or transform people, goods, and information for specific reasons and purposes. They show that proximity is not always synonymous with coevality, intimacy, or knowledge exchange. The following sections will contextualize urban-rural collaborations in Indonesia by critically exploring some of the historical continuities and changes in art and media engagements with the countryside in West Java.

5 Protschky (2011:26) observes close links between colonial landscape-painting and photography and cartography. In the seventeenth century, painters and map makers often had similar training, while the maps and paintings themselves overlapped in functions and aesthetics. Maps were used as decorative wall-hangings and status symbols, while paintings traced the contours of islands, coasts, and landscapes, or included maps and map-making as representational objects or themes (Protschky 2011:26-9). 
In 2013, the Common Room Networks Foundation was commissioned by the Badan Perencanaan Pembangunan Daerah Provinsi Jawa Barat (Regional Development Planning Agency of the Province of West Java) to explore the possibility of developing ecotourism in 16 regencies in the province of West Java. According to the new-media art community, 'the core strategy is to combine art, culture and utilization of ICT/media tech to support rural and agriculture development; as well [as] to nurture creativity, innovation and social entrepreneurship in [an] urban and rural context'. ${ }^{6}$ One of the focus points of this project has been collaboration with the Kasepuhan Cipagelar community in rural West Java. The community serves as an exemplary model for the Indonesian government's plan for the nationwide development of 'smart villages'. While initially providing a service to the Regional Development Planning Agency, the Common Room Networks Foundation has continued independent research and arts collaboration with Kasepuhan Ciptagelar. ${ }^{7}$

Kasepuhan Ciptagelar refers to the modern name of a traditional community in the Mount Halimun-Salak National Park area. 'Sepuh' means 'old' in Sundanese, and kasepuhan refers to a group of elders or a community connected through ancestral customs. The earliest historical records of this community date back to $1368 .^{8}$ The community has a migratory character and follows a form of hereditary male leadership. The current head of Kasepuhan Ciptagelar is Abah Ugi Sugriana Rakasiwi (b. 1985). ${ }^{9}$ The community leader follows ancestral instructions (wangsit) to determine the location of the centre of government, or Kampung Gede ('the big village'). This centre has shifted to various locations over time. According to the administrative and territorial system of the Indonesian nation-state, the current Kampung Gede, with a population of several hundred people, is based in the village of Sirnaresmi in the Sukabumi regency. ${ }^{10}$ The broader Kasepuhan Ciptagelar community, consist-

'2015 GALA ASIA introduction'. http://greenartlaballiance.eu/wp-content/uploads/2015/ 11/GALA-ASIA-Introduction.pdf (accessed 14-9-2018).

7 Iskandar, personal communication, 13-8-2018.

8 'Tentang Kasepuhan Ciptagelar'. https://ciptagelar.info/tentang/ (accessed 14-9-2018).

9 Abah is an honorary title which means 'father' in Sundanese. While the role of sesepuh girang (adat leader) is hereditary, the community can vote for their village elders (kokolot lembur), who participate in community decision-making processes during adat meetings (Suganda 2009:33).

10 Dinas Pariwisata dan Kebudayaan Provinsi Jawa Barat, 'Kampung Gede Kasepuhan Ciptagelar', 9-8-2011. http://www.disparbud.jabarprov.go.id/wisata/dest-det.php?id=475\&lang= id (accessed 14-9-2018). 
ing of approximately 16 , ooo people, is spread over villages across three different regencies in the provinces of Banten and West Java. Some community members live outside West Java, in other regions and islands in Indonesia (Suganda 2009:28). ${ }^{11}$

The name Ciptagelar, adopted in 2001, is a contraction of the Sundanese verbs nyiptakeun (to create) and ngagelarkeun (to show). It refers to a specific historical phase during which the main village was created in the open, and the community was willing to present itself to the outside world (Nuryanto 2008:50). ${ }^{12}$ The name confirms that the community itself has a desire for coevality. In other words, the idea for creative and social collaboration has not been externally imposed but is the result of a two-way process of careful considerations.

One aspect of the Kasepuhan Ciptagelar community that has attracted the attention of outsiders, including artists, academics, and tourists, is the unique ways in which the community interacts with the natural environment. This interrelationship also influences, and has been influenced by, the community's social structures and religious beliefs, which include a mix of Islam, Hinduism, and Sunda Wiwitan animist beliefs. Ugis Suganda Amas Putra (Suganda 2009:41), a member of the Ciptagelar community who is also a West Java representative in the Aliansi Masyarakat Adat Nusantara (AMAN, Alliance of Adat Societies of the Archipelago) explains:

The Ciptagelar Kasepuhan indigenous community believes that humans are only one of many living creatures in the universe. In their value system, human beings should respect 'Mother Earth' and 'Father Heaven' just as they respect their own parents. Perceptions of nature must always be related to people's perceptions of themselves as human beings. The underlying concept is Jagat Leutik, Jagat Gede-Jagat Leutik Sanubari, Jagat Gede Bumi Langit: awareness of the microcosm and macrocosmthe small world of consciousness and the immensity of the natural universe.

\footnotetext{
11 Kasepuhan Ciptagelar is also part of the network Kesatuan Adat Banten Kidul (Customary Law Association of South Banten), which connects it to other communities with shared or similar histories, traditions, and customary laws (adat) in more than 5 oo villages in the South Banten region. Some of the other traditional communities include Kasepuhan Cisungsang, Kasepuhan Cisitu, Kasepuhan Cicarucub, Kasepuhan Citorek, Kasepuhan Sirnaresmi, Kasepuhan Ciptamulya, Kasepuhan Cibedug. See ‘Tentang Kasepuhan Ciptagelar'. https://ciptagelar.info/tentang/ (accessed 14-9-2018).

This also implies that in the future the community may decide to close itself off again.
} 
As part of this philosophy, which is a source of contemporary thinking about environmental sustainability, the community makes a distinction between three different types of forest: protected forest, reserved forest, and land for agricultural and agroforestry purposes (Suganda 2009:37). ${ }^{13}$ Rice plants are seen as a personification of the goddess of fertility, Nyi Pohaci Sanghyang Asri. According to customary law, the community members can use the rice for personal consumption but are not allowed to turn it into a commodity to sell to others. Unlike modern, intensified rice cultivation, Kasepuhan Ciptagelar has only one rice-growing cycle per year. The remaining six or seven months of the year are deemed necessary for soil restoration and bringing nature back in balance. $^{14}$

Rice plants are stored for up to a year, or even longer, in small family barns (called leuit in Sundanese or lumbung in Indonesian). This approach to cultivation has secured the survival of a strong variety of rice species and has made the community self-sufficient and resilient to plagues and droughts. The whole cycle of growing, harvesting, and storing rice is guided by astrology and accompanied by festive rituals. The largest annual celebration is Seren Taun, which marks the transition between agricultural years. Through prayers and rituals, community members express their gratitude for the harvest of the previous year and request blessings for the next agricultural cycle. The Seren Taun ceremony is open to visitors, who are welcomed with an abundance of food and entertainment. The festival has been highly publicized in the Indonesian mainstream and social media and has become a major attraction for domestic and international tourists, scholars, and artists (Suganda 2009:59).

\section{5 Digital Mapping}

The Regional Development Planning Agency, with assistance from organizations such as the Common Room Networks Foundation, seeks to support Kasepuhan Ciptagelar's economic development by creating an urban market

13 People can enter the protected forest with permission from the community leader, but they are not allowed to take anything from it. Non-timber products can be harvested from the reserved or closed forest. The open forest can be used for various purposes, such as paddy fields, rotational agriculture, agroforestry, livestock, housing, and roads (Suganda 20o9:45-6).

14 Ridzki R. Sigit, 'Seren Taun: Tradisi syukur panen padi Ciptagelar yang eksis sejak 644 tahun yang lalu, Mongabay', 5-9-2012. http://www.mongabay.co.id/2012/og/o5/seren-taun -tradisi-syukur-panen-padi-ciptagelar-yang-eksis-sejak-644-tahun-yang-lalu-bagian-1/ (accessed 14-9-2018). 
for local agroforestry products such as wild rattan and Arenga palm sugar. It aims to make the packaging, branding, and online marketing appeal to the tastes of urban consumers. Iskandar acknowledged that one of the challenges and responsibilities in this process was to explain and find consumer acceptance for the limitations to agricultural growth, production, and availability that come with protecting local culture and respecting nature's carrying capacity. ${ }^{15}$ I believe another challenge is to avoid a situation where local food and goods merely add to urban consumer choice, and function to satisfy the capitalist desire for offering ever-greater product quantity and diversity. Considering the global extension of neo-liberal market structures, it is extremely challenging for this and other worthwhile initiatives to contribute to radical, qualitative changes to existing production and consumption mechanisms.

The Common Room Networks Foundation and Kasepuhan Ciptagelar have also collaborated in installing so-called Mini Data Centres, which are powered by solar energy. ${ }^{16}$ The open-source data centres, solar panels, and relevant ICT infrastructure were set up in several steps throughout 2016. The data centres are meant to assist with indigenous knowledge management as well as making information about Kasepuhan Ciptagelar accessible to the outside world. They also support the 'collaborative and objective' mapping of the community's geographical territory. ${ }^{17}$ These initiatives were in line with the strong technological interests of the head of Kasepuhan Ciptagelar, Ugi Sugriana. Sugriana himself had facilitated the introduction of Ciptagelar's own short-range community radio and television stations-Radio Swara Ciptagelar (RSC FM, established in 2004) and CIGA TV (established in 2008), respectively. ${ }^{18}$ These broadcast

15 re:publica, 'Nourishing our communities: Rural and urban platforms for food innovation', 16-5-2017. https://www.youtube.com/watch?v=iQRPWyPwsec\&feature=youtu.be (accessed 14-9-2018).

16 Iskandar explained this at the re:publica 17 digital-culture conference in Berlin (8-10 May 2017), in a joint session titled 'Nourishing Our Communities—Rural and Urban Platforms for Food Innovation'. The session focused on 'new forms of bottom-up agriculture networks based on ucd [User-Centered Design] methods and ict tools bringing urban drivers in dialogue with rural practitioners in order to collaboratively develop more sustainable technological solutions to small-scale farming around the world'. See re:publica, 'Nourishing our communities: Rural and urban platforms for food innovation'. https://re-publica .com/en/session/nourishing-our-communities-rural-and-urban-platforms-food -innovation (accessed 14-9-2018). The other presenters in this panel were from Ethiopia, Senegal, and Germany.

17 re:publica, 'Nourishing our communities: Rural and urban platforms for food innovation', 16-5-2017. https://www.youtube.com/watch?v=iQRPWyPwsec\&feature=youtu.be (accessed 14-9-2018).

18 In community media, media ownership, management, and production of content are in 
stations were built from recycled materials and are powered by small hydroplants. The concept behind the radio and television broadcasts is nyoreang alam katukang, nyawang mangsa nu bakal datang (looking at the past world, anticipating the future) - to seek a balance between tradition and modernity, and to visually and discursively inform the younger generation about community values and customs. ${ }^{19}$ Such community-specific content is not provided by Jakarta-based television and radio stations with a national reach.

Kasepuhan Ciptagelar's active and innovative involvement in the development of energy and communication sources contrasts with art projects by external organizations that tend to present a priori technical solutions, singularize or abstract local participants, or approach the subjectivity of these participants as 'a problem in need of repair' (Kester 2011:136). Kester (2011:12536) observed some of these tendencies in the efforts by Danish art collective Superflex to promote biogas in Tanzania. Development projects in Indonesia share similar levels of complexity. For instance, the development organization Kopernik has collaborated with local artists such as Balinese rock musicians Navicula in trying to promote low-cost technological solutions to rural communities. On its homepage, Kopernik refers no less than five times to 'last mile' communities, ${ }^{20}$ while its partners include multinationals like Exxon-Mobil, JP Morgan Chase, and Freeport Indonesia. ${ }^{21}$ This triggers the question whether or to what extent the Kopernik projects acknowledge local wisdom in their aim 'to change the status quo in the development sector',22 or whether or to what extent these projects challenge the broader business mechanisms and power structures underlying issues of poverty and environmental destruction in the first place.

The recent introduction of the Mini Data Centres and other digital technology in Kasepuhan Ciptagelar was, in the spirit of coevality, guided by careful

the hands of the members of a group or society. In the Indonesian Broadcasting Law of 2002, this media category is acknowledged and distinguished from state-run and commercial media. The participatory character of community media combines well with the open-source philosophy and practice of new-media art collectives such as the Common Room Networks Foundation.

19 Yogasmana, personal communication, 25-9-2018. Broadcast content documents aspects of daily life (dokumentasi sadidinten in Sundanese), especially the five major seasonal activities: ngaseuk (rice-planting), mipit (rice harvest procession), nganyaran (new harvest rice-tasting), serah ponggokan (end-of-agricultural-year census, village inventory, and harvest festival budgeting) and seren taun.

$20 \quad$ 'About'. https://kopernik.info/en/about/mission-values (accessed 14-9-2018).

21 'Partners'. https://kopernik.info/en/partners (accessed 14-9-2018).

22 'About'. https://kopernik.info/en/about/mission-values (accessed 14-9-2018). 
discussion between the parties with relevant expertise across various fields. Apart from the Common Room Networks Foundation, the conversation partners included Indonesia ICт Watch, the Fakultas Teknologi Industri Pertanian (Faculty of Agro-Industrial Technology) of Padjadjaran University, the Lembaga Budaya Sunda (Sundanese Culture Institute) of Pasundan University, and the Teknik Geodesi dan Geomatika (Geodesy and Geomatics Engineering) department of the Institut Teknologi Bandung (Bandung Institute of Technology). During a meeting in the Gambung region, south of Bandung, in April 2016, the various partners reached consensus on four priorities: environmental protection and conservation, cultural preservation and development, local ICT infrastructure and renewable energy development, and local economic empowerment and livelihood improvement. ${ }^{23}$

The project partners started their cultural-space-mapping project in December 2016. They combined modern technology, such as Global Positioning System (GPS) tagging and drone-mounted cameras, with traditional territorial border-marking by the Ciptagelar community, such as prayers and offerings to ancestral spirits in the forest. Photos of these traditional activities can provide legal evidence to support indigenous land claims. During this twenty-day project (December 2016-January 2017), approximately 3,00o hectares of land were mapped. The mapping also assisted with the analysis of hydrological sources for farming and examining the relationship between weather conditions and rice production results. ${ }^{24}$ The cultural-space-mapping project serves as a model for the Badan Informasi Geospasial (Geospatial Information Agency) 'One Map' programme for consistent, nation-wide spatial data management (Nugroho and Hikmat 2017).

The use of modern technology — such as radio, television, photography, video, digital data centres, drones, GPS, and the Internet-has greatly enhanced the information available about, and the accessibility of, the West Javanese rural community. During the New Order, traditional groups such as Kasepuhan Ciptagelar faced not only the challenge of geographical isolation but also socio-political marginalization. The Soeharto regime implemented

23 re:publica, 'Nourishing our communities: Rural and urban platforms for food innovation', 16-5-2017. https://www.youtube.com/watch?v=iQRPWyPwsec\&feature=youtu.be (accessed 14-9-2018).

24 re:publica, 'Nourishing our communities: Rural and urban platforms for food innovation', 16-5-2017. https://www.youtube.com/watch?v=iQRPWyPwsec\&feature=youtu.be (accessed 14-9-2018). It is said that at the peak of El Niño, in 2005, Kasepuhan Ciptagelar secured good harvests because of their use of traditional knowledge, whereas the rice production in other parts of Indonesia largely failed. 
policies aimed at limiting and controlling public attention to, and discussion of, issues relating to ethnicity, religion, race, and ideological 'inter-group' relations (suku, agama, ras dan antar-golongan, or SARA; Sen and Hill 2000:12). After the fall of the New Order in 1998, Indonesia's democratic reform, or Reformasi, has stimulated greater freedom of expression and instigated processes of decentralization and regional autonomy. It has provided more space for indigenous communities to profile themselves and to fight for their rights, as confirmed by the establishment of the national organization for indigenous communities AMAN in 1999 (Avonius 2003). Kasepuhan Ciptagelar's possibilities and desire for coevality has literally put the community on the map, has encouraged creative and social partnerships for local development and environmental sustainability, and has facilitated self-reflection for all parties involved.

\section{$6 \quad$ Visual Disturbance}

The Joko Widodo government's interest in using big data and creating a consistent geospatial 'One Map' of the nation-state (Nugroho and Hikmat 2017) can further enhance the visibility of indigenous groups but may also prove a double-edged sword. While the various digital maps give the impression of precision, objectivity, and comprehensiveness, their composition relies on the specific selection, input, and editing of data. The interpretation, application, and practical consequences of this mapping process depend on the ideological frameworks of national and regional policy-making. Similar to the distanced horizons and bird's-eye perspectives in Beautiful Indies paintings, satellite imagery and drone footage often leave actual people out of sight and may obscure the socio-political dimensions behind the various forms of mapping. In some cases, it may lead to the naturalization or even aestheticization of harmful human interference in the natural environment (Demos 2017:136). Seemingly straightforward techno-fixes may hide the complexity and seriousness of the environmental problems they are concerned with, and even reinforce the social and political practices causing these problems in the first place.

The main ideological conflict between the Indonesian government and Kasepuhan Ciptagelar that is steered by, but not visually captured in, processes of mapping concerns the very concept of 'nature'. The government has been expanding the Mount Halimun-Salak National Park in an effort to protect West Java's precious flora and fauna. However, the new boundaries of the park have been interfering with the transborder migration and agroforestry traditions of Kasepuhan Ciptagelar, which themselves are key factors for environmental sus- 
tainability (Suganda 2009). The government idea of preserving nature in its authenticity is in conflict here with communal ideas about balanced cohabitation between people and nature.

Another example of visuality disturbing rather than promoting coevality is the abundance of amateur and art videos, news broadcasts, and documentaries on the Internet documenting and promoting tourism to the Mount HalimunSalak area. While some groups of visitors aim at engaging with the local community and expanding their knowledge about cultural traditions and the natural environment, there is also a remarkable quantity of YouTube videos presenting the West Javanese countryside predominantly as an exciting and exotic rally destination. The videos are produced by the members of clubs of almost any motorcycle and $4 \times 4$ vehicle brand present on the Indonesian roads. They typically involve the real-time recording of the trip from the urban centre of departure to the rural destination. The motorcyclists and rally drivers have introduced an unprecedented visual perspective by positioning their web cameras at their motor helmets or behind car windows and grills, slightly above or below eyesight. Apart from identifying the name of the car or motorcycle brand or club, the titles of these videos typically present the nature ('trip to') and idyllic destination ('paradise') of the journey. The main purpose of these 'pro-am' (professional-amateur) productions is to present individual stories and group identity to other netizens. While the reach of these creative videos is potentially limitless, their accessibility may not necessarily go beyond the number of recipients of the community media and new-media art initiatives in Kasepuhan Ciptagelar, due to the sheer abundance of competing forms of audio-visuality on the Internet.

Unlike the distanced horizons and bird's-eye views of Beautiful Indies paintings and modern drones, the videos are highly experiential and provide microscopic detail of roads, bricks, mud, traffic signs, and other vehicles. They express the desire to cover the distance and conquer the destination, which, thanks to modern communication and transportation technology, has become both physically and psychologically within reach. Obviously, the close-up and decontextualized footage of motorcycles and cars eating up the asphalt and ploughing the landscape goes against the basic principles of ecotourism and environmental sustainability. One could argue the footage represents a shift from the Beautiful Indies to the 'Beautiful Anthropocene', 'celebrating' the age in which human activity is thought to be the dominant influence on the Earth's geology and ecosystems.

While the Beautiful Indies style seems to present the countryside as a distanced and sensual object of desire, the mobile webcams provide a form of 'porno-tropics' (McClintock 1995:21) with explicit and detailed footage of the 
penetration of the landscape. The tourist-media prosumers-whose consumption practices feed into their own forms of media production-traverse the landscape at high speed, while not aiming at, or succeeding in, establishing transversal connections or deterritorializing and transformative intimacy and knowledge-sharing with the people or nature at their destination site (Guattari 1989:134; Genosko 2000:146-7, 151). According to Yogasmana, handling the impact of visitors is one of Kasepuhan Ciptagelar's major challenges. ${ }^{25}$ This challenge is accepted wholeheartedly, however, as it perceived as a logical consequence of the age of 'cipta gelar'.

The previous section demonstrated how digital mapping can serve as a tool of governance or an experiential form of communication between netizens. In either case, there is only a limited sense of coevality between the producers and objects of the media content. This brings us to the question to what extent Indonesian and international urban artists have the capacity to produce creative and critical transversality with rural communities such as Kasepuhan Ciptagelar. Can the contemporary art projects provide a more comprehensive picture of the entanglements between social, political, and natural environments? And is there consistency between the environmental themes or ambitions expressed and the social and creative practices and forms or styles of audio-visuality on which they are based?

According to Heather Davis and Etienne Turpin, 'attuning ourselves, through poetry, art, and description, to pay attention to other times; developing techniques to begin to think through the limits of our temporal frameworks, and then thinking beyond them [...] are crucial practices; in fact, they are matters of survival' (Davis and Turpin 2015:12-3). They argue that art is central to 'thinking with and feeling through the Anthropocene', as aesthetics constitutes a tool to counteract people's 'anaesthetization' or sensory adaption to the human impact on the natural environment (Davis and Turpin 2015:3). At the same time, the politics of the imagery and art itself, which is at the centre of conceptualizing or opposing the Anthropocene, often remains contradictory or unacknowledged (Demos 2017:17). Both Davis and Turpin (2015) and Demos (2017) point to the (hidden) politics of visual and textual discourses neutralizing, dehistoricizing, and depoliticizing the key factors behind the Anthropo-

25 Personal communication, 25-9-2018. 
cene. This includes universalizing images of the earth, devoid of any disagreements or conflicts, as in the 1972 Blue Marble photograph taken from outer space (Demos 2017:19-20).

In other discourses, humanity as a whole is deemed responsible for our current condition, without differentiation between specific actors, or the degrees to which they are responsible for, or affected by, anthropogenic disaster (Demos 2017:21). Yet other texts and imagery celebrate human mastery over 'our' earth and sanctify an exclusive group of technocrats and scientists in saving the planet through geo- and bio-engineering (Demos 2017:21). Davis and Turpin, Demos, and other academics have also addressed the potentially misleading, depoliticizing character of the term 'Anthropocene' itself. They prefer other terms with the benefit of either identifying the culprit, such as the Capitalocene, Technocene, Eurocene, Plantationocene, Homogenocene, or Plasticene, or promoting alternative, presumably more environmental-friendly forms of governance, such as the Gynecene (Davis and Turpin 2015:7-9; Demos 2017:85-95).

A similar range of perspectives is provided by the various creative and informational genres using the footage of drones in the Ciptagelar area, including music clips, documentary films, news broadcasts, and home videos. A form of art expressing the desire for coevality are the landscape videos accompanied by the music of the Bandung-based experimental group Sound of Hanamangke. ${ }^{26}$ The video clip for one of their songs, 'Halimun', takes the viewer on an audio-visual journey through the hills of the Mount Halimun-Salak National Park. ${ }^{27}$ The music follows the pace, perspective, and objects of the visual representation, which includes bird's-eye views of mountains, forests, villages, roads, and rice fields. The sounds and images reflect the reality of Kasepuhan Ciptagelar as a synthesis of tradition and modernity. Conceptually, the flying camera connects the various hamlets that are part of the Ciptagelar network and represents the migratory character of the community. Com-

26 The group consists of Bintang Manira Manik (drum and percussion), Yudi Taruma Di Swara (flute [kecapi] and vocals), Wawan Kurniawan (drum [kendang], two-stringed violin [tarawangsa], and didgeridoo), Daeng Rendy (guitar), and Lutfi Aditya (bass guitar). The band's name is derived from a philosophical quote from an Old-Sundanese palm leaf manuscript, 'tan hana nguni tan hana mangke aya', which means that there is no present without a past. The performers attempt to combine traditional and modern musical instruments and styles in a form of 'world jazz'. See Ngayogjazz, 'Sound of Hanamangke'. http://jogjakartaevent.blogspot.com/2012/11/ngayogjazz-2012-dengan-jazz-kita.html (accessed 14-9-2018).

27 Yoyo Yogasmana, 'Ciptagelar Drone 3', 25-4-2015. https://www.youtube.com/watch?v=e33 QPUGuPKI (accessed 14-9-2018). 
bined with the philosophical idea behind Hanamangke, the music and imagery promote awareness of the past as an invaluable source of the present and the future, both in terms of artistic preservation-innovation and socialenvironmental sustainability.

The music videos were uploaded by Yoyo Yogasmana (b. 1970), a long-time resident and liaison officer of Kasepuhan Ciptagelar. Yogasmana was born in Tasikmalaya, to a family of adat elders. ${ }^{28}$ After graduating in fine arts from the Institut Keguruan dan Pendidikan (IKIP, Institute of Teacher Training and Education) in Bandung, he became a well-travelled performance artist, with art residencies in Asia, Europe, and North America. ${ }^{29}$ Apart from being a spokesperson and English translator for the community and its leader, Yogasmana is also in charge of CIGA TV. His own background as well as Ugi Sugriana's interest in, and experimentation with, modern technology have shaped the dynamic and open character of Kasepuhan Ciptagelar.

A different type of coevality is expressed in Ciptagelar remixed, a communityrelated art project in which the Common Room Networks Foundation has been involved. In 2015 Kasepuhan Ciptagelar produced its own Sundanese pop music ( $p o p$ Sunda) video album, containing video clips of performers singing about life in the community against a background of local landscapes, people, daily life activities, and rituals. Since then, the community has invited artists from other places, including Bandung, Berlin, Sydney, and Melbourne, to col-

28 According to the adat, his task was to facilitate communication with the outside world. When his community entered the age of opening up (cipta gelar), he was asked to return and continue the same task from inside the core territory of Kasepuhan Ciptagelar (Yogasmana, personal communication, 25-9-2018).

29 Zetizen, 'Sosok Yoyo Yogasmana, juru bicara Kasepuhan Ciptagelar yang kerap keliling dunia', Z., 24-2-2016. https://www.zetizen.com/show/55/sosok-yoyo-yogasmana-juru -bicara-kasepuhan-ciptagelar-yang-kerap-keliling-dunia (accessed 14-9-2018). Yogasmana's performance art, called 'trial performance', explores 'the levels of human emotion and feelings that are provoked in people when they see someone being hurt' (Meyer 2013; Yogasmana, personal communication, 25-9-2018). In some of his performances, he has himself tied up in ropes that are then controlled by the audience. According to the artist, the physical pain caused by audience members pulling the ropes is a representation of Indonesian society and politics, in which economic survival is prioritized over human dignity and values (Meyer 2013). This performance theme may explain why Yogasmana accepted to return to a community that does not attach monetary value to basic needs such as rice. 
laborate and create their own interpretations of the songs, with styles ranging from jungle, hip hop, and reggae to industrial, ambient, and electro. In 2017 the community worked on the Ciptagelar remixed project with Sydney-based musician and statistician Dan MacKinlay, the Common Room Networks Foundation, and Robi Rusdiana, the leader of the Bandung-based death-metal acapella choir Ensemble Tikoro. ${ }^{30}$ The idea of 'remix' itself designates a desire to bring different times and places in innovative dialogue with each other.

One of the other artists involved, Melbourne-based musician and radio producer Kieran Ruffles, also created his own sound project, titled Sunda sway. This audio-work was broadcast on Australian Broadcasting Corporation's (ABC) Radio National on 7 October 2016 and is available as a podcast on the $\mathrm{ABC}$ website. ${ }^{31}$ Listeners can follow Ruffles on his journey from Bandung to Ciptagelar, where he attended the Seren Taun rice harvest festival. The work includes recordings of Ensemble Tikoro and pantun, gamelan, and wayang performances at the harvest festival. The use of sounds, music, voice, and narration gives an intimate impression of pranatamangsa, or traditional Sundanese ways of measuring time, relating to the lifecycle of musical instruments, the growth of plants, human and animal biorhythms, and astrology, among others. ${ }^{32}$ The Common Room Network Foundations' Iskandar provides a background to the traditional ways of time- and season-keeping in regular intervals of soliloquies or snippets of conversation with Ruffles. Ruffles narrates how Ugi Sugriana had a dream during the Seren Taun festival, which contained the ancestral command (wangsit) to move the Kasepuhan Ciptagelar government to a different centre, in line with the community's ongoing tradition of migration. The themes of temporality and transition are replicated in various ways throughout

30 'Ciptagelar remixed'. http://107.org.au/event/ciptagelar-remixed/ (accessed 14-9-2018).

31 ABC Radio National, 'Sunda sway', Soundproof, 7-10-2016. [Measuring Time in Sound Series.] http://www.abc.net.au/radionational/programs/archived/soundproof/sunda -sway/7880598 (accessed 14-9-2018).

32 Another Australian artist, Anna Madeleine, during a 2017 Asialink Arts Residency with the Common Room Networks Foundation, produced an Augmented Reality (AR) art work based on the same traditional farming calendars, titled Pranatamangsa AR (2017). In the work, which can be downloaded as a mobile phone application, virtual objects illustrating the various seasons overlay the maps of related stellar constellations in a small booklet. The full-length animation (2018), with voice-overs by Iskandar explaining the various growth cycles, was presented at the Melbourne International Animation Festival 2018; see 'Pranatamangsa AR, 2018'. http://www.annamadeleine.com/pranatamangsa-ar/ (accessed 14-9-2018). Unlike Ruffles's work, Madeleine's work feels more like an autonomous art work inspired by traditional calendars rather than the product of a direct collaboration with the local community. The idea of augmented reality itself responds well with the Kasepuhan Ciptagelar interest in digital mediations of reality. 
the audio-work, including sounds and narration relating to the producer's road trip to Ciptagelar, and the use of drone-copters by locals and guests to traverse and explore the rural area from above. The Radio National host concludes the broadcast by explaining that the ABC Facebook site contains 'captivating footage of Ciptagelar taken by, yep, dronecopters'. ${ }^{33}$

Sunda sway is 'contemporary', in Smith's (2016) sense of juxtaposing or bridging different notions of time and space in a work of art. It creates awareness about systems and devices for tracking time and space and organizing society and human-nature relations outside the hegemonic Western temporal and spatial paradigms that support capitalist cycles of production and consumption. At the same time, the work does not discuss Kasepuhan Ciptagelar's legal-political struggles over land rights, which are related to the community's alternative notions of space and time. It also does not explore the practical and ideological dimensions of using the community as a model for socio-political reorganization and environmentally sustainable solutions. Similar to the YouTube road videos, the perspective provided remains firmly in the hands of the artist-narrator, who refers to the many challenges in reaching the destination, including 'two flat tyres'. Rather than delving into the visual politics of droneand car-mounted cameras, the Radio National host seems to adhere to technoexoticism in her rather ironic response to the local community's use of dronecopters.

Towards the Coeval Commons?

While Sunda sway partially succeeds in making accessible, and creatively explaining, life in Kasepuhan Ciptagelar, other art projects with much-larger funding seek to explore how creative networking and collaboration between traditional and contemporary artists and communities worldwide can generate solutions to pressing global issues such as anthropogenic disaster. One of the recent international art projects in which Yogasmana represented Kasepuhan Ciptagelar was Age of Wonderland in Eindhoven. Age of Wonderland was a multi-year project (2014-2018), initiated by Baltan Laboratories, HIVos, and the Dutch Design Foundation. It was meant to promote social innovation and sustainable development through interdisciplinary research and international networking in art and design. Each year, six artists from Asia, Africa, and Latin

33 ABC Radio National, 'Sunda sway', Soundproof, 7-10-2016. [Measuring Time in Sound Series.] http://www.abc.net.au/radionational/programs/archived/soundproof/sunda -sway/7880598 (accessed 14-9-2018). 
America were invited for a six-week residency in the Eindhoven region. They collaborated with Dutch artists and companies on a special sub-theme and presented the outcomes of their work during the Dutch Design Week. Themes included 'The Friendly Invasion of a New World Order' (2014), 'Balancing Fair and Green Food' (2015), 'Big DATA. Big DADA?' (2016) and '10o Days of Learning' (2017).

In the 2015 edition, Yogasmana worked with students from the Design Academy Eindhoven (DAE) (Adel et al. 2018:6-8). ${ }^{34}$ During the 2015 Dutch Design Week, he gave a public rice-cooking presentation and narrated stories about the 'ancestral and ecologically sound traditions in food production and consumption' of his community, including the preservation of 130 varieties of rice without the use of insecticides (Adel et al. 2018:20). In their project publication, the organizers highlighted how Kasepuhan Ciptagelar 'challenged visitors to question the way we treat food in western society' (Adel et al. 2018:32). According to the organizers of Age of Wonderland, the global collaboration and exchange of ideas beyond the established, Western centres of financial capital and knowledge was necessary to maintain Eindhoven's position as an international centre of innovation.

While Age of Wonderland provided ample space for the international collaborators to participate and present their stories and expertise, the details of their often challenging immediate socio-political surroundings were not included in the final project publication. While the publication alluded to the conditions of (post)colonialism, it did not address the irony that contemporary global solutions for environmental sustainability were to come from regions such as West Java, which had seen its biodiversity strongly reduced by the 'Plantationocene' or 'Homogenocene' of the monoculture plantations introduced by Dutch colonialism. The prominent display of food in the festival triggers questions that are also relevant to the Regional Development Planning Agency's involvement in the marketing of rural products in urban centres. Will this display merely satisfy the curiosity of consumer-visitors for having a taste of exotic varieties of familiar items, or can it bring fundamental change to established, environmentally unfriendly production and consumption ideas and practices?

At the festival, Kasepuhan Ciptagelar was awarded the first Eco coin, 'a [symbolic] currency for nature ecology value' (Adel et al. 2018:20), by the then newly established Next Nature Network. In the context of Age of Wonderland it is contradictory, if not cynical, that a coin, albeit a symbolic one, was used to award a community known for its traditional, non-monetary forms

34 In a follow-up project, two DAE students took up a residency in Ciptagelar (Adel et al. 2018:32). 
of exchange. The use of an award system itself generates associations of neoliberal exploitation and remuneration. On its homepage, the Amsterdambased Next Nature Network describes itself as a platform for exploring the interconnections between nature and technology. ${ }^{35}$ It claims to be 'the only group that approaches the concept of nature in a new manner'. The same Internet page shows a video of the network's director presenting on stage in a style not dissimilar to that of the CEOs of multinationals such as Facebook and Microsoft. ${ }^{36}$ The network's themes of interest include 'Hypernature: Manufactured nature that is better than the real thing' and 'Manufactured animals: Making man's best friend even better' ${ }^{37}$ Its online shop sells products such as a 'glowing planet T-shirt' (to 'highlight the enchanting beauty of our glowing planet') and a 'brand memory game. ${ }^{38}$ Rather than furthering the ideal of 'the coeval commons' (Smith 2016:14), these promotional strategies and audio-visual tactics reinforce dominant ideological hierarchies and neo-liberal regimes in contemporary art and society. They fall short of the radical cultural and socio-political changes needed for tackling the environmental challenges of our times.

Demos (2017:7-8) identifies the same approaches and shortcomings in the web portal 'Welcome to the Anthropocene', which also presents itself as a 'world's first' in education on the Anthropocene. Similar to the Next Nature Network, 'Welcome to the Anthropocene' is sponsored by an international group of research organizations and makes use of PR-style promotional media. ${ }^{39}$ Demos (2017:21) notices that the texts and images on this and related websites of partner organizations present a universalizing discourse, which 'avoids the politicization of ecology that could otherwise lead to the practice of climate justice, which demands that the politics of equality, human rights, and historical responsibility be taken into account when addressing environmental change'. Another example discussed by Demos (2017:44-7) and closely related to the Next Nature belief in geo- and bio-engineering is 'An ecomodernist manifesto', claiming 'to use humanity's extraordinary powers in service of creating a good Anthropocene. ${ }^{40}$ Christophe Bonneuil and Jean-Baptiste Fressoz (quoted

35 'About'. https://www.nextnature.net/welcome/ (accessed 14-9-2018).

36 'Next Nature: The nature caused by people'. https://www.youtube.com/watch?v=N3pUf663 9hM (accessed 14-9-2018). [TEDx talk by Koert van Mensvoort at TEDx Danubia 2013, 214-2013.]

37 'Themes'. https://www.nextnature.net/themes/ (accessed 14-9-2018).

38 'Shop'. https://www.nextnature.net/shop/ (accessed 14-9-2018).

39 'Welcome to the Anthropocene'. http://www.anthropocene.info/ (accessed 14-9-2018).

40 John Asafu-Adjaye et al., 'An ecomodernist manifesto', April 2015. http://www.ecomodern ism.org/ (accessed 14-9-2018). 
in Demos 2017:30) refer to such groups as 'anthropocenologists', who 'manufacture a global nature-system that is no longer a commons regulated by collective debate, practices, and rights, but one whose exclusive access is strictly regulated as a function of the rights, subject to emergency circumstances, to alter, pilot, and optimize the whole of the planet and its atmosphere'.

A different approach, more in line with the ideal of the coeval commons, is presented by CASCO, the Office for Art, Design, and Theory (established in Utrecht in 1990), another Dutch organization working with Indonesian artists on global issues such as social and environmental justice. In the period 20132015, CASCO collaborated with the Stedelijk Museum Bureau Amsterdam and KUNCI Cultural Studies Center in Yogyakarta on the Made in Commons programme, publications, and exhibitions. It showcased the work of ten Indonesian and European artists and art collectives, who all engaged with the commons theme, including collaboration, the sharing of resources, labour, ownership, authorship, (artistic) control, open participation, knowledge-sharing, power hierarchies, and decentralization (Thajib and Winking 2014:2). Their art work explored, and was inspired by, the collective mobilization of resources through a variety of media and platforms, such as the Internet, traditional crafts, agricultural cooperatives, and other collectives. It included a critique of capitalism and a search for alternatives to the monetization of social relations and the access to natural resources (Thajib and Winking 2014:3).

According to CASCO,

The aim of our work is to contribute to forming non-capitalist cultures and possibilities for life for which we believe art could play an essential role, not as an insular avant-garde but in alignment with other initiatives and social movements. Instead of accumulation, alienations, apathy, and competition, a culture that we envision is comprised of sharing, caring, and living and working together. In this light, we see our organization and space as a micro society that might reflect such vision. It's a tough but worthwhile venture.

quoted in SMITH 2016:73

In the search for the coeval commons, this type of modest, political, and truly collaborative approach provides a necessary alternative to the exclusivist, homogenizing, and 'me first' methods propagated in the name of the Anthropocene by some of the geo- and bio-engineering initiatives. 
While Indonesian contemporary art is a predominantly urban phenomenon, in recent years both local and international artists, collectives, and festivals have increased their interest in creative collaborations with rural counterparts and communities. The objectives of these collaborations, which often involve a mixing of contemporary and traditional forms of art and knowledge, are both artistic and socio-economic. The issues that are being addressed are highly topical and of local, national, and/or global relevance, including environmental destruction and ecological solutions.

Artistic engagements with the Indonesian countryside date back to the Beautiful Indies painting style during Dutch colonialism. This style offered distant perspectives and dehumanized themes of representation that obscured the colonial impact on the indigenous society and natural environment. Contemporary art collaboration provides access to, and insight in, rural communities and also gives the communities the opportunity to (re)present themselves, even on a global stage. The contemporary perspectives and objects of (self-)representation are steered by modern technologies such as digital data centres and drone- and car-mounted cameras. While capable of presenting unprecedented detail, spatial reach, and temporal coverage, the current artistic and amateur audio-visualizations do not necessarily provide a comprehensive picture of the socio-political contexts of cultural, economic, and natural deterioration.

The Common Room Networks Foundation's collaboration with Kasepuhan Ciptagelar is an outstanding example of careful, ongoing, and in-depth urbanrural creative and social negotiation and innovation. However, the same type of inclusivity and intimacy is not guaranteed in the further remediation of objects and images. Will the coverage of satellites and web cameras strengthen indigenous land claims or serve the potentially antithetical policies and commercial interests of governments and businesses? Will the packaging and branding of rural products instigate more sustainable production and consumer habits or mainly serve the capitalist need for the diversification of commodities and markets? Will these and other types of audio-visual and material mediation promote ecotourism or push environmentally destructive auto-mobility to the remotest of locations? And will urban-rural artistic entanglements develop the spirit of the coeval commons or, rather, fortify existing ideological hierarchies in contemporary art and society? It is important to note here that the problem of fortifying hierarchies does not lie in the technologies themselves but in the power structures and ideological attitudes of institutions that set up art collaborations with smaller collectives and rural communities. 
Ambiguous examples discussed in this article include how the administrative borders of Mount Halimun-Salak National Park limit the low-footprint migratory and agricultural traditions of Kasepuhan Ciptagelar; the increasing flow of polluting and destructive car and motorbike rallies to the West Javanese countryside; and the partial, decontextualized or distorted representations of the traditional community and its artists in international art projects and festivals. The Common Room Networks Foundation and Age of Wonderland have been innovative and productive in establishing interdisciplinary and cross-border collaborations relating to the most urgent issues of our times. At the same time, the task remains for the artworks, festivals, collaborations, and social-media campaigns inaugurated by these and other initiatives to create awareness about some of the more specific challenges mentioned above, including the socio-political impact of creative production and display itself.

\section{Acknowledgements}

I would like to acknowledge Yoyo Yogasmana, Gustaff Harriman Iskandar, Reina Wulansari, and Patricia Spyer for their invaluable feedback on my research. I also thank the Graduate Institute in Geneva for giving me the opportunity to write and present drafts of this article during my stay in September-October 2018.

\section{References}

Adel, Coralie den, Olga Mink, Renée Roukens and Christine Wagner (2018). Age of Wonderland: Celebrating four years of global innovation 2014-2017. Eindhoven: ageofwonderland.nl.

Avonius, Leena (2003). 'Reforming adat: Indonesian indigenous peoples in the era of Reformasi', The Asia Pacific Journal of Anthropology 4/1-2:123-42.

Brakel, Koos van (2009). 'Mooi Indië-kunst: Een koloniaal medium?', in: Meta Knol, Remco Raben and Kitty Zijlmans (eds), Beyond the Dutch: Indonesië, Nederland en de beeldende kunsten van 1900 tot $n u$, pp. 50-9. Amsterdam and Utrecht: KIT Publisher and Centraal Museum.

Davis, Heather and Etienne Turpin (2015). 'Art and death: Lives between the Fifth Assessment and the Sixth Extinction', in: Heather Davis and Etienne Turpin (eds), Art in the Anthropocene: Encounters among aesthetics, politics, environments and epistemologies, pp. 3-29. London: Open Humanities Press. 
Demos, T.J. (2017). Against the Anthropocene: Visual culture and environment today. Berlin: Sternberg Press.

Fischer, Joseph (1990). 'The traditional sources of modern Indonesian art', in: Joseph Fischer (ed.), Modern Indonesian art: Three generations of tradition and change 19451990, pp. 14-41. Jakarta: Panitia Pameran KIAS and Festival of Indonesia.

Genosko, Gary (2000). 'The life and work of Félix Guattari: From transversality to ecosophy', in: Félix Guattari, The three ecologies, pp. 106-59, translated by Ian Pindar and Paul Sutto. London and New Brunswick, NJ: The Athlone Press.

Guattari, Félix (1989). 'The three ecologies', translated by Chris Turner, New Formations 8 (Summer):131-47.

Jurriëns, Edwin (2014). 'Mediating the metropolis: New media art as a laboratory for urban ecology in Indonesia', in: Larissa Hjorth, Natalie King and Mami Kataoka (eds), Art in the Asia-Pacific: Intimate publics, pp. 173-9o. London and New York: Routledge.

Jurriëns, Edwin (2017). Visual media in Indonesia: Video vanguard. London and New York: Routledge.

Jurriëns, Edwin (2019). 'Intertwined ecologies: Environmental aesthetics in Indonesian contemporary art', Third Text 33-1:59-77.

Kester, Grant H. (2011). The one and the many: Contemporary collaborative art in a global context. Durham and London: Duke University Press.

McClintock, Anne (1995). Imperial leather: Race, gender and sexuality in the colonial contest. London and New York: Routledge.

Meyer, Helge (2013). 'Empfindnis and self-inflicted pain in performance art', in: Maria Pia Di Bella and James Elkins (eds), Representations of pain in art and culture, pp. 3951. New York and London: Routledge.

Nugroho, Yanuar and Agung Hikmat (2017). 'An insider's view of e-governance under Jokowi: Political promise or technocratic vision?', in: Edwin Jurriëns and Ross Tapsell (eds), Digital Indonesia: Connectivity and divergence, pp. 21-37. Singapore: ISEAS Yusof Ishak Institute.

Nuryanto (2008). 'Ruang publik dan ritual warga kampung Kasepuhan Ciptagelar di Kabupaten Sukabumi', Jurnal Penelitian Pendidikan 8-1 (July):48-59.

Protschky, Susie (2011). Images of the tropics: Environment and visual culture in colonial Indonesia. Leiden: KITLV Press.

Sen, Krishna and David T. Hill (200o). Media, culture and politics in Indonesia. Melbourne: Oxford University Press.

Smith, Terry (2008). 'Introduction: The contemporaneity question', in: Terry Smith, Okwui Enwezor and Nancy Condee (eds), Antinomies of art and culture: Modernity, postmodernity and contemporaneity, pp. 1-22. Durham, NC: Duke University Press.

Smith, Terry (2013). 'Contemporary art: World currents in transition beyond global- 
ization', in: Hans Belting, Andrea Buddensieg and Peter Weibel (eds), The global contemporary and the rise of the new art worlds, pp. 186-92. Cambridge, MA: MIT Press.

Smith, Terry (2016). The contemporary composition. Berlin: Sternberg Press. [The Contemporary Condition Series.]

Spanjaard, Helena (2016). Artists and their inspiration: A guide through Indonesian art history 1930-2015. Volendam: LM Publishers.

Suganda, Ki Ugis (2009). 'The Ciptagelar Kasepuhan indigenous community, West Java: Developing a bargaining position over customary forest', in: Emilianus Ola Kleden, Yuyun Indradi and Liz Chidley (eds), Forests for the future: Indigenous forest management in a changing world, pp. 27-63. Jakarta and Hallbankgate: The Indigenous Peoples Alliance and Down to Earth.

Thajib, Ferdiansyah and Kerstin Winking (2014). Global collaborations: Made in Commons. Amsterdam: Stedelijk Museum Bureau Amsterdam.

Wright, Astri (1994). Soul, spirit, and mountain:Preoccupations of contemporary Indonesian painters. Kuala Lumpur: Oxford University Press. 